\title{
1 Development of the first antibody targeting vitellogenin using the Palinurus 2 elephas mRNA molecular pathway
}

3 Faustina B Cannea ${ }^{1}$, Cristina Follesa ${ }^{1 \dagger}$, Cristina Porcu ${ }^{1 \dagger}$, Rossano Rossino ${ }^{2}$, Alessandra Olianas ${ }^{1}$,

4 Antonio Rescigno ${ }^{3}$ and Alessandra Padiglia ${ }^{1^{*}}$

$5{ }^{1}$ Dipartimento di Scienze della Vita e dell'Ambiente (DiSVA), Biomedical section, University of Cagliari,

6 Cittadella Universitaria di Monserrato, 09042 Monserrato, Cagliari, Italy

7

$8{ }^{1 \dagger}$ Dipartimento di Scienze della Vita e dell'Ambiente (DiSVA), Marine Bioecology section, University of

9 Cagliari, via T. Fiorelli 1, 09126, Cagliari, Italy

10

$11^{2}$ Dipartimento di Scienze Mediche e Sanità Pubblica (DSMSP), University of Cagliari, AOU Presidio microcitemico via Jenner, 09121 Cagliari Cagliari, Italy

Corresponding author: Alessandra Padiglia, padiglia@unica.it

Keywords: Palinurus elephas, vitellogenin, antibody anti-vitellogenin, ELISA, mRNA, CODEHOP

\section{ABSTRACT}

Vitellogenin is an essential protein involved in ovary maturation in many animals. Detection of this protein correlated with reproductive capacity may be important if carried out on marine organisms such as the red spiny lobster Palinurus elephas, a crustacean economically important crop from wild fish catches. Moreover, in recent years, vitellogenin has assumed an important role as a possible biomarker of marine environmental pollution, as its expression levels can be influenced by the presence of similar oestrogen pollutants and affect the reproductive sphere of marine organisms such as crustaceans. The P. elephas vitellogenin protein and its coding gene have never been isolated, so there is little information about its presence in this lobster. The aim of the present study was to develop a molecular strategy to create, for the first time, an antibody for the detection and quantization of vitellogenin in P. elephas. 


\section{INTRODUCTION}

The determination of vitellogenin (VTG) levels in marine aquatic species has for some time aroused much interest from both the fishery and environmental points of view. The study of VTG has now definitively found wide application in controlling the reproductive biology of fish, including the management of natural populations, the development of appropriate breeding practices and the quality control of the aquatic environment (Hiramatsu et al., 2002). VTG is a physiological indicator of the maturation stage of the female gonad (Reading et al., 2017) therefore, the possibility of measuring its concentration variations in many species throughout the life cycle makes VTG a far more sensitive indicator of sexual development with respect to endocrine parameters such as oestradiol, testosterone and gonadotropins (Denslow et al., 1999; Matozzo et al., 2008). VTG is a glycolipophosphoprotein (300-700 kDa) synthesized in the reproductive phase of many vertebrate and invertebrate animals. Expressed in the ovary and in the extraovarian sites of females in decapod crustaceans (Guan et al., 2016; Jia et al., 2016), VTG exhibits similar molecular features in phylogenetically related organisms, signifying its important physiological role in the course of evolution (Chen et al., 1997). Extraovarian synthesis involves the transport of VTG into the ovary through a blood vessel or haemolymph, in which it is internalized in the oocyte via receptor-mediated endocytosis (Barber et al., 1991; Ruan et al., 2020). Inside the oocyte, VTG undergoes a post-translational modification that consists of glycosylation events, the addition of lipids and proteolytic cleavages that generate smaller proteins collectively called vitelline $(\mathrm{Vt})$, which are the main protein component for the development and maturation of eggs (Meusy et al., 1988; Wilder et al., 2002; Tiu et al., 2008). The proteolytic cuts originating from Vt occur in specific domains of the VTG precursor. The VTG amino acid sequence of the lobster Homarus americanus $(\mathrm{HaVg} 1)$ deduced from cDNA highlighted the presence of several potential cleavage sites of the subtilisin endopeptidase (characterized by the consensus sequences RXXR or RXK/RK/R) from which at least three subunits with estimated molecular sizes of 80, 105 and $90 \mathrm{kDa}$ could be produced starting from the precursor (Tiu et al., 2009). The precursor VTG is expressed at low levels in males and immature females, while it reaches high levels of expression during oogenesis in mature females (Thongda et al., 2015). Oestrogen $17 \beta$-oestradiol and oestrogen-like molecules are powerful inducers of vitellogenesis in immature females since they can stimulate the expression of VTG (Palmer et al., 1998). In males, the genes for VTG (Vtgs) are normally silent, but in response to oestrogen or oestrogen-like substances, they undergo excessive transcriptional activity, and as a result, the protein synthesis occurs in the liver or functionally similar organs. Abnormal expression of this protein in males makes VTG a strong biomarker due to its ability to undergo variations in gene expression in aquatic species that live in aquatic environments contaminated by oestrogens and oestrogen-like molecules (Denslow et al., 1999; Sumpter and Jobling, 1995). In recent decades, greater attention has been given to assessing the adverse effects of chemicals that interfere with the endocrine system (EDCs: endocrine disrupting chemicals) in aquatic environments (Park et al., 2019). The concentration of VTG measured in the plasma of male fish under physiological conditions is 10-50 ng/mL, while in reproductive females, it is approximately $20 \mathrm{mg} / \mathrm{mL}$ (Denslow et al., 1999; Folmar et al., 1996; Parks et al., 1999). Studies on Homarus americanus have shown that VTG is undetectable in 
haemolymph from adult males instead increased 40-fold during the reproductive phase (Tsukimura et al., 2002). Since VTG levels have been shown to be closely related to the reproductive conditions of different crustaceans (Tsukimura, 2001; Tsukimura et al., 2002), their quantification could be a useful tool for monitoring the reproductive status of species living in specific environments. The European lobster Palinurus elephas (Fabricius, 1787) is a long-lived and slowgrowing species typical of temperate waters that is widely distributed in the Mediterranean Sea and the Atlantic Ocean. The development of increasingly powerful and efficient fishing methods in recent years has led to a decrement in the stocks of this crustacea in Sardinia (Italy) and other countries of the Mediterranean basin (Cau et al., 2019).

The main objective of this research was to develop a specific antibody for the detection of VTG in the eggs of the P. elephas lobster since the study of this protein has now definitively found wide application not only in controlling the reproductive biology of marine animals but also in monitoring the quality of aquatic environments. A specific antibody for P. elephas VTG could be a useful tool for the following reasons: 1) to investigate the reproductive suitability of the population of this crustacean since VTG is a good indicator of female reproductive activity, and 2) to evaluate nonphysiological protein amount in males since VTG is considered a biomarker of environment pollution. Moreover, the isolation of mRNA coding for VTG allowed us for the first time in this crustacean to enrich the gene databases with a part of the coding sequence from which it was possible to derive the corresponding primary structure of the encoded protein.

\section{MATERIALS AND METHODS}

The VTG content present in the eggs of $P$. elephas was determined in ELISA experiments through the use of specific antibodies designed with a molecular strategy developed in our laboratory. Unlike standard methods that require the purification of proteins from specific tissues as a starting point for the production of specific antibodies, the method we used exploits synthetic peptides of which the primary sequence was deduced for the first time in our laboratory starting from a fragment of $P$. elephas Vtg gene (GenBank accession number: KX792013.1), which corresponds to the N-terminal region of others VTG sequences deposited in GenBank. Synthetic peptides have been used as antigenic molecules for the production of specific polyclonal antibodies.

\section{Animals}

The study was conducted on the Mediterranean P. elephas egg clutches samples that were provided by the Marine Biology section of the Department of Life and Environmental Sciences of the University of Cagliari. The animals were captured in the period October to March, corresponding to the extruding period of the species (Goñi et al., 2003) inside and outside of two different fully protected areas (FPAs) located in the central western (Su Pallosu) and in the southwestern coasts (Buggerru) of Sardinia (Cau et al., 2019; Follesa 
et al., 2007). In particular, the concentration of VTG was estimated from the egg clutches of 30 ovigerous females at the same stage of intermediate development (stage 2) as follows: 16 ovigerous females were caught inside of FPAs (60.9.-91.9 mm carapace length) and 14 outside of FPAs (68.7-100.3 mm carapace length), all at the same developmental stage (Table S1A). The presence of external eggs on the pleopods and carapace length (CL) was used as an indicator of maturity (Kang et al., 2008). The developmental stage of the eggs of P. elephas (Follesa et al., 2007) was estimated using a binomial generalized linear model (R Core Team, 2017, https://www.R-project.org/) with a logistic link established through evaluating the von Bertalanffy growth parameters calculated for females. The relationship between the egg size at each developmental stage and the female lobster size was evaluated by regression analysis, and significant differences were calculated by t-tests (Zar, 1999). VTG levels were also determined in the hepatopancreas and haemolymph of 6 male $P$. elephas, of which 3 were captured inside and 3 were captured outside of the marine protected areas. Once collected, the biological samples were stored at $-20^{\circ}$.

\section{Isolation of total RNA from ovarian tissue and RT-PCR}

Total RNA was extracted from $50 \mathrm{mg}$ of $P$. elephas eggs using TRI Reagent (Sigma-Aldrich, St. Louis, MO) following the manufacturer's suggested protocol. The quality of purified RNA was verified by gel electrophoresis using a 1\% denaturing agarose gel stained with SYBR Green II (Sigma-Aldrich), and the concentrations were measured using a NanoDrop 2000c UV-VIS Spectrophotometer (Thermo Scientific, Waltham, MA, USA) at $260 \mathrm{~nm}$. To obtain cDNAs, P. elephas RNAs were reverse transcribed with an oligo dT primer using an enhanced avian myeloblastosis virus reverse transcriptase enzyme (Sigma-Aldrich) following the manufacturer's instructions.

\section{Palinurus elephas Vtg cDNA amplification by PCR with hybrid primers}

For detecting the unknown nucleotide sequences of the Vtg gene, a degenerate hybrid oligonucleotide primer (CODEHOP) strategy (Rose et al., 2003) was used, starting from aligning the multiple sequences of VTG proteins. In particular, nine different crustacean sources were chosen from the GenBank SwissProt database which were aligned using Clustal Omega (http://www.ebi. ac.uk/clustalw) (Fig. S1) and then cut into blocks using Block Marker software (http://blocks. fhcrc.org/blocks/). The primers were designed using the default parameters of the j-CODEHOP server (https://4virology.net/virology-ca-tools/j-codehop/). Amplification primers used for $P$. elephas Vtg cDNA were chosen from a group of primer candidates provided by the $\mathrm{j}$ CODEHOP programme (Table 1).

Each primer presents the consensus clamp given in the upper case, whereas the degenerate core is in the lower case: $\mathrm{y}=[\mathrm{C}, \mathrm{T}] ; \mathrm{r}=[\mathrm{A}, \mathrm{G}]$, and $\mathrm{n}=[\mathrm{A}, \mathrm{G}, \mathrm{C}, \mathrm{T}]$. PCR was performed in a solution containing $1.5 \mathrm{mM}$ $\mathrm{MgCl}_{2}, 100 \mathrm{mM}$ Tris- $\mathrm{HCl}, \mathrm{pH} 8.3,50 \mathrm{mM} \mathrm{KCl}, 200 \mathrm{mM}$ dNTP mix, $1 \mathrm{mM}$ sense primer, $1 \mathrm{mM}$ antisense 
primer, $1 \mu \mathrm{g}$ of $P$. elephas cDNA, and 1-3 units of Jump Start AccuTaq LA DNA polymerase mix (SigmaAldrich). Thermal cycles of amplification were carried out in a Personal Eppendorf Mastercycler (Eppendorf, Hamburg, Germany) using slightly different programmes. The PCR experiments, conducted using all the pairs of sense and antisense oligonucleotides chosen by j-CODEHOP software, allowed us to obtain a single reaction product with the F3-R2 primer pair (Fig. S1), with dimensions of approximately 300 bp, which was compatible with those of a possible expected product. The PCR products detected on $6 \%$ polyacrylamide or $2 \%$ agarose gels were purified with a Charge Switch PCR Clean-Up kit (Invitrogen, Carlsbad, CA) and then sent to BMR genomics (Padova, Italy) for sequencing. Translation of nucleotide sequences was performed using OMIGA or ExPASy translate routine software (http://ca.expasy.org/) (Fig. 1A). Sequences were aligned with Clustal Omega (https://www.ebi.ac.uk/Tools/msa/clustalo/), and similarities were analysed with the advanced BLAST algorithm available at the National Center for Biotechnology Information website (http://www.ncbi.nlm.nih.gov/) and with the FASTA algorithm v.3.0 from the European Bioinformatics Institute website (http://www.ebi.ac.uk/fasta33/index.htlm).

\section{Peptide synthesis}

The P. elephas VTG amino acid sequence deduced in silico (Fig. 1A) was used to create two synthetic peptides (Fig 1B) (Genscript USA Inc.) to be employed for the production of specific anti-VTG antibodies (Twin Helix, Rho, Italy). The epitopes were predicted by the GenScript Optimum AntigenTM design tool (antigenic peptide 1 AA9-AA23 and antigenic peptide 2 AA50-AA63). Comprehensive analysis was performed on multiple aspects, including antigenicity, hydrophilicity, hydrophobicity, the probability of antibody accessibility (exposure on the protein surface) and the uniqueness of the protein sequence. The useful information related to the synthetic peptides for the synthesis of antibodies is shown in Fig. 1B.

\section{P. elephas VTG detection by ELISA.}

For the detection of VTG, we performed indirect ELISA using the commercial Prepro Tech TMB ELISA Buffer Kit (DBA, Italy) following the manufacturer's suggested protocol. For the standard curve, the antigenic peptides diluted in $2 \%$ blocking medium in phosphate buffered saline buffer (PBS, pH 7.4) were added to the wells of the plate at scalar concentrations in the range of 1-250 ng per well and then incubated for one hour at $37{ }^{\circ} \mathrm{C}$. After three consecutive washes in PBS, the antibodies diluted in $2 \%$ blocking medium in PBS at a concentration of $0.1 \mu \mathrm{g} /$ well were incubated on the plates overnight at $4{ }^{\circ} \mathrm{C}$. After the incubation period, the plates were washed five times, and secondary antibodies made of anti-mouse IgG conjugated with HRP diluted in PBS (1:20000) were added to the wells of the plate for 2 hours at $37{ }^{\circ} \mathrm{C}$. Finally, the plates were washed six times and then incubated with the tetramethylbenzidine (TMB) substrate HRP. The reaction was carried out in phosphate-citrate buffer $(\mathrm{pH}$ 5.5) in the dark for 15 minutes at room temperature and 
subsequently blocked with $10 \%$ sulfuric acid. The plates were read at a wavelength of $460 \mathrm{~nm}$ using the VICTOR 3 V 1420 Multi-Label Microplate Reader (Perkin Elmer, USA). All reactions were carried out in triplicate using both antigenic peptides in separate experiments. The blank samples were composed of buffer or water with no protein sample included. The standard curve R2 values obtained were the same for antigenic peptide $1(\mathrm{R} 2=0.9757)$ and peptide $2(\mathrm{R} 2=0,97)$. When the homogenate of $P$. elephas eggs was used as an antigen, the ELISA plates were coated with $25 \mathrm{mg}$ of biological sample per well. Specifically, the eggs were sonicated in RIPA buffer supplemented with a protease inhibitor (Bio-Rad Laboratories, Inc.) in the proportion of $25 \mathrm{mg}$ of eggs per 100 microlitres of buffer. After homogenization, the tubes were centrifuged at $14000 \mathrm{x} \mathrm{g}$ for 20 minutes, and the supernatant obtained was used following the steps previously described for the peptides used to construct the standard curve. To validate the ELISA, we determined the intra-assay coefficient of variation $(\mathrm{CV})$ value, which was less than $15 \%$.

\section{RESULTS AND DISCUSSION}

The aim of the present work was to design a specific antibody for the detection of VTG in P. elephas females at the same stage of intermediate development (stage 2). The samples with external eggs in the intermediate stage (diameter $0.92-1.30 \mathrm{~mm}$ ) were selected since the levels of VTG in crustaceans appear to decrease significantly with the beginning of the oviposition of the animals (stage 3) (Tsukimura et al., 2002). The objective was achieved after isolating the coding mRNA, which, after being reverse transcribed, was subjected to PCR that utilized copies of partially degenerated primers designed with the CODEHOP strategy (Rose et al., 2003) starting from aligning the multiple sequences of VTG proteins (Fig. S1). The results of the PCR fragment sequencing allowed us to reconstruct in silico a part of the primary structure of the protein, corresponding to a peptide of 63 amino acids (Fig. 1A). By aligning the sequence obtained with protein sequences deposited in NCBI databases (https://blast.ncbi.nlm.nih.gov/Blast.cgi) and UniProt (https://www.UniProt.org/), we found a homology identity of 60-70\% with the amino terminal portion of other crustacean VTGs (Fig. S2).

Analysis of the amino acid sequence to establish the presence of antigenic regions revealed the potential presence of two epitopes. This allowed the biotechnological synthesis of two peptides (the antigenic peptide 1 AA 9-AA23 and antigenic peptide 2 AA50-AA63) (Fig. 1B) that were used to create two different antibodies (anti-VTG1 and anti-VTG2) for ELISA experiments to detect the VTG expressed in the females of $P$. elephas in the second stage of egg maturation. Different concentrations of peptide 1 or peptide 2 were used in the presence of the specific antibody (anti-VTG1 or anti-VTG2), to construct the standard reference curve. The standard curve R2 values obtained were the same for antigenic peptide $1(\mathrm{R} 2=0.9757)$ and peptide $2(\mathrm{R} 2=0,97)$. Biological samples used in ELISA experiments were obtained from 30 females and 6 males of $P$. elephas captured inside and outside of the marine protected areas surrounding the coasts of Sardinia. The external eggs attached to the pleopods were removed from the females; the haemolymph was 
taken from the males. By relating the absorbance of each sample with an unknown concentration to the standard curve previously established, we obtained the amounts $(\mathrm{ng} / \mathrm{mL})$ of VTG contained in the eggs of $P$. elephas. These were found in a range of 200-260 ng in 14 of the 30 females analysed, while in the other 16 , the concentrations ranged from 120-180 ng/mL (Table S1 B). Differences in VTG levels in stage 2 eggs could be correlated with the sexual maturity of females within the same stage of development. The VTG concentration did not vary between the females captured inside (IN) and outside (OUT) FPAs. In fact, analysis of the VTG concentration in relationship with the inside and outside FPAs did not show statistic differences (Fisher's exact test statistic $=1 ; \mathrm{p}>0.05$ ). According to those found for Homarus americanus males (Tsukimura et al., 2002), the absorbance values obtained for P. elephas males were so low that it was not possible to calculate concentration values to correlate with the standard curve. All ELISA experiments were conducted in parallel using both available antibodies, and the VTG concentrations detected were the same in the presence of each anti-VTG antibody. An overview of steps involved in the development of P.elephas anti-VTG antibodies is shown in Fig. 2.

\section{Conclusion}

In this work, a study aimed at the creation of the anti-VTG antibodies of P. elephas was carried out for the first time starting from the partial isolation of the mRNA coding for VTG. This strategy allowed a part of the primary structure of the protein to be defined and the biotechnological synthesis of two peptides that, thanks to their high antigenic potential, were used to generate two different antibodies. With this molecular pathway, we have bypassed the protein purification procedure from tissue or other biological samples where the protein is expressed, which is usually used to generate antibodies (Denslow et al., 1999; Tsukimura et al., 2002; Kang et al., 2008). As reported in the literature (Denslow et al., 1999), the quantization of VTG through ELISA represents a powerful tool that can be used to achieve further objectives in ecological and marine biological studies of $P$. elephas, due to the following:

1) The tool makes it possible to compare the levels seen in individuals of $P$. elephas taken from different repopulation areas, both in protected areas (internal) and in areas dedicated to commercial fishing (external), to verify the possible role of the protein in reproduction and growth and increase the number of individuals in the population itself.

2) The tool can monitor the concentrations of this protein in individuals grown in both restocking and free areas to verify whether any increase in protein levels could be related to the presence of oestrogen-like substances in the water.

In fact, the use of VTG as a biomarker can indicate not only the presence of a pollutant in the water but also the effect that it can have on physiological alterations related to the reproductive sphere. The VTG values obtained in the various samples during this study did not highlight any significant differences between the 
expression levels of mature females living inside and outside protected marine areas. The values found allowed to establish, for the first time, a concentration range for VTG considering the eggs of females in ovarian stage 2 , probably correlated with sexual maturity within the same stage of development. The analyses carried out on male individuals did not provide detectable results. A future goal will be to analyse a greater number of individuals to constantly monitor any fluctuations in the concentration of this important protein both in mature females and in males and to determine if environmental conditions determine its expression.

The authors declare that they have no competing interests.

\section{Funding}

This research was partially supported by FIR (Fondi integrativi per la Ricerca) funded by the University of

\section{Author Contributions}

Conceptualization, F.B.C., A.P., C.F. and C.P.; methodology, F.B.C. and A.P.; software, R.R. and A.O; validation, F.B.C., A.P. and C.F.; formal analysis, F.B.C. and C.F.; investigation, F.B.C., A.P., C.F. and C.P; resources, C.F., A.P., R.R; data curation, F.B.C. and A.P.; writing-original draft preparation, AP.; writing-review and editing, A.R.; visualization, F.B.C., A.P. and C.F.; supervision, A.P.; project administration, A.P and C.F; All authors have read and agreed to the published version of the manuscript.

\section{References}

Barber, D.L.; Sanders, E.J.; Aebersold, R.; Schneider, W.J. (1991). The receptor for yolk lipoprotein deposition in the chicken oocyte. J. Biol. Chem., 266, 18761-18770. DOI:10.1016/S0021-9258(18)55128-0 Protected Areas. Sci. Rep., 9, 13025. DOI:10.1038/s41598-019-49553-8

Chen, J.S.; Thomas, W.; Raikhel, A.S. (1997). Extensive sequence conservation among insect, nematode, and vertebrate vitellogenins reveals ancient common ancestry. J. Mol. Evol., 44, 440-451. DOI: 
Denslow, N. D.; Chow, M.C.; Kroll K.J.; Green L. (1999). Vitellogenin as a biomarker of exposure for estrogen or es-trogen mimics. Ecotoxicol., 8, 385-398. DOI:10.1023/A:1008986522208

Follesa, M. C.; Cuccu, D.; Cannas, R.; Sabatini, A.; Deiana, A.M.; Cau, A. (2009). Movement patterns of the spiny lobster Palinurus elephas (Fabricius, 1787) from a central western Mediterranean protected area. Sci. Mar., 73, 499-506. DOI:10.3989/scimar.2009.73n3499

Follesa, M.C.; Cuccu D.; Cannas, R.; Cau, A. (2007). On the growth of the European spiny lobster, Palinurus elephas from Sardinian waters (central western Mediterranean Sea). N. Z. J. Mar. Freshwater Res., 41, 377-383. DOI: 10.1080/00288330709509927

Folmar, L.C.; Denslow, N.D.; Rao, V.; Chow, M.; Crain, D. A.; Enblom, J.; Marcino, J. Guillette, L.J.Jr. (1996). Vitellogenin induction and reduced serum testosterone concentrations in feral male carp (Cyprinus carpio) captured near a major metropolitan sewage treatment plant. Environ. Health Perspect., 104, 1096-1101. DOI: 10.1289/ehp.961041096

Goñi, R.; Quetglas, A.; Reñones, O. (2003). Size at maturity, fecundity and reproductive potential of a protected population of the spiny lobster Palinurus elephas (Fabricius, 1787) from the western Mediterranean. Mar.Biol.,143, 583-592. DOI:10.1007/s00227-003-1097-5

Guan, Z.-B.; Yin, J.; Chen, K.; Shui, Y.; Cai, Y.J.; Liao, X.-R. (2016). The hepatopancreas and ovary are the sites of vi-tellogenin synthesis in female red swamp crayfish (Procambarus Clarkia (Girard, 1852)) (decapoda: astacoidea: cambaridae) J. Crustacean Biol., 36(5), 637-641. DOI: 10.1163/1937240X-00002459

Hiramatsu, N.; Matsubara, T.; Weber, G.M.; Sullivan, G.V.; Hara, H. (2002). Vitellogenesis in acquatic animals. Fish. Sci., 68, 694-699. DOI:10.2331/fishsci.68.sup1_694 vitellogenin gene from Scylla paramamosain . Gene, 520, 119-130. DOI: 10.1016/j.gene.2013.02.035 Vitellogenesis in both sexes of gonochoristic mud shrimp, Upogebia major (Crustacea): analyses of vitellogenin gene expression and vitellogenin processing. Comp. Biochem. Physiol., 149, 589-598. DOI: 10.1016/j.cbpb.2007.12.003 exposure to estrogenic compounds in aquatic invertebrates: a review. Environ. Int., 34, 531-545. DOI: 10.1016/j.envint.2007.09.008 
Palmer, B.D.; Huth, L.K.; Pieto, D.L; Selcer, K.W. (1998),Vitellogenin as a biomarker for xenobiotic estrogens in an amphibian model system. Environ. Toxicol. Chem. 17, 30-36. DOI: https://doi.org/10.1002/etc.5620170105

Park, K.; Jo, H.; Kim, D.K.; Kwak, I.S. (2019). Environmental pollutants impair transcriptional regulation of the vitel-logenin gene in the burrowing mud crab (Macrophthalmus Japonicus) Appl. Sci., 9, 1401. DOI:10.3390/app9071401www.mdpi.com/journal/applsci

Parks, L.G.; Cheek ,A.O.; Denslow, N.D.; Heppell, S.A.; Mc Lachlan, J.A.; Le Blanc, G.A.; Sullivan, C.V. (1999). Fathead minnow (Pimephales promelas) vitellogenin: purification, characterization and quantitative immunoassay for the detection of estrogenic compounds. Comp Biochem Physiol C Pharmacol Toxicol Endocrinol., 123(2):113-25. DOI: 10.1016/s0742-8413(99)00010-9

R Core Team (2017) R: A Language and Environment for Statistical Computing

Reading, B.; Sullivan, C.; Schilling, J. (2017). The reproductive organs and processes: vitello-genesis in fishes. Encyclo-pedia of Fish Physiology: From Genome to Environment; Ferrell, A.P., Ed.; Elsevier: Maryland Heights, MO, USA, , 1-12. DOI:10.1016/B978-0-12-374553-8.00257-4

Rose, T.M.; Henikoff, J.G.; Henikoff, S. (2003). CODEHOP (COnsensus-DEgenerate Hybrid Oligonucleotide Primer) PCR primer design. Nucleic Acids Res., 31, 3763-6. DOI: 10.1093/nar/gkg524

Ruan, Y.; Wong, N.K.; Zhang, X.; Zhu, C.; Wu, X.,. Ren, C.; Luo, P.; Xiao, J.; Jiatai, J.; Xugan, W.; Chaoqun, H.; Ting, C. (2020). Vitellogenin Receptor (VgR) mediates oocyte maturation and ovarian development in the Pacific white shrimp (Litopenaeus vannamei) Front. Physiol., 11, article 485. DOI: 10.3389/fphys.2020.00485

Sumpter, J. P.; Jobling, S. (1995). Vitellogenesis as a biomarker for estrogenic contamination of the aquatic environment. Environ. Health Perspect., 103 (suppl 7): 173-178. DOI: 10.1289/ehp.95103s7173

Thongda, W.; Chung, J.S.; Tsutsui, N.; Zmora,N.; Katenta, A. (2015). Seasonal variations in reproductive activity of the blue crab, Callinectes sapidus: vitellogenin expression and levels of vitellogenin in the hemolymph during ovarian development. Comp. Biochem. Physiol. A Mol. Integr. Physiol., 179, 3543. DOI: $10.1016 /$ j.cbpa.2014.08.019

Tiu, S.H.K.; Benzie, J.; Chan, S.M. (2008). From hepatopancreas to ovary: molecular characterization of a shrimp vi-tellogenin receptor involved in the processing of vitellogenin. Biol. Reprod., 70, 66-74. DOI 10.1095/biolreprod.107.066258

Tiu, S.H.K.; Hui H.L.; Tsukimura, B.; Tobe, S. S.; He, J.G.; Chan, S.M. (2009) Cloning and expression study of the lobster (Homarus americanus) vitellogenin: conservation in gene structure among decapods Gen. Comp. Endocrinol., 160, 36-46. DOI: 10.1016/j.ygcen.2008.10.014 
Tsukimura, B. (2001). Crustacean vitellogenesis: its role in oocyte development. Am. Zool., 41, 465-475.

Tsukimura, B.; Waddy, S.L.; Vogel, J.M.; Linder, C.J.; Bauer, D.K.; Borst, D.W. Characterization and quantifi-cation of yolk proteins in the lobster, Homarus americanus. J Exp Zool. 2002, 1; 292(4) 367-75. DOI:10.1002/jez.10047

Wilder, M.N.; Subramoniam, T.; Aida, K. (2002). Yolk proteins of crustacea. In: Raikhel, A.S., Sappington, T.W. Re-productive Biology of Invertebrates, 12 Part A. Progress in vitellogenesis Science

Zar, J.H. (1999). Biostatistical Analysis 4th edition. Pearson 


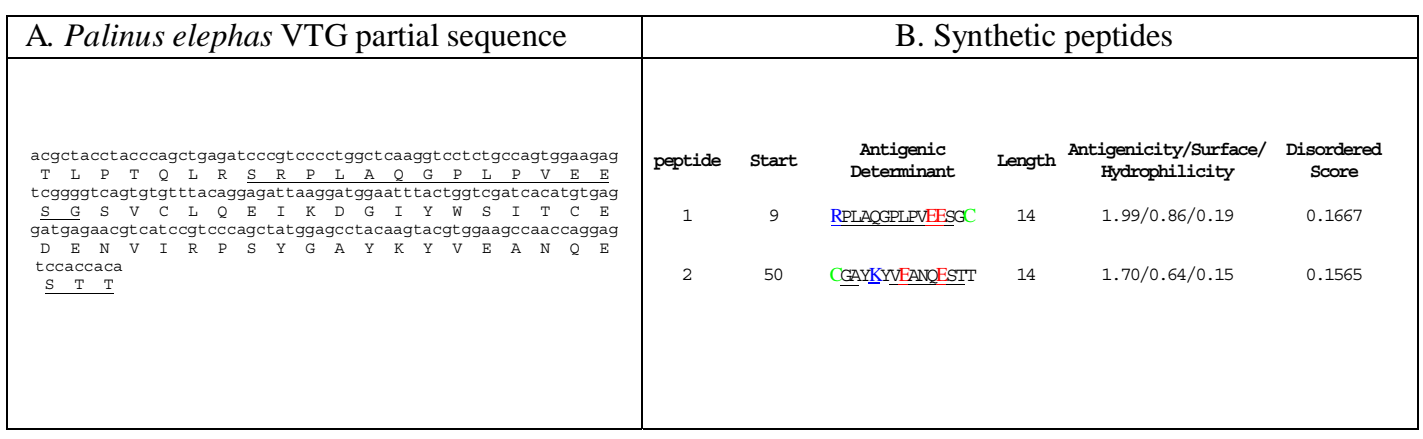

Fig. 1. (A) Nucleotides and, below, deduced amino acid sequences of VTG from P. elephas. The underlined regions are predicted to be antigenic regions. (B) Information related to the synthetic peptides. An extra ' $\mathrm{C}$ ' (highlighted in green) is added to the $\mathrm{C}$ terminus (or $\mathrm{N}$ terminus) to facilitate conjugation. The antigenic positively charged residues $(\mathrm{K}, \mathrm{R})$ and negatively charged residues $(\mathrm{E})$ are in blue and in red respectively. The synthesis and epitopes predictions were made using GenScript. Residues of VTG enzyme and synthetic peptides are reported with the one letter code. 
A

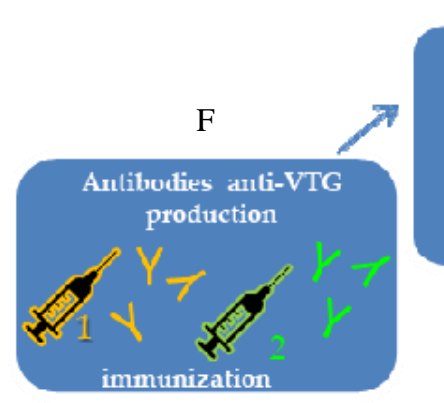

409

Fig. 2. An overview of steps involved in the development of P.elephas anti-VTG antibodies. (A) Total RNA was extracted from P. elephas eggs. (B) To obtain cDNAs, P. elephas RNAs were reverse transcribed; for detecting the unknown nucleotide sequences of the Vtg gene, CODEHOP PCR was used, starting from aligning the multiple sequences of VTG proteins. (C) The PCR products obtained were used for the preparation of sequencing samples. (D) The nucleotide sequence acquired experimentally was translated into the amino acid sequence and aligned with protein sequences deposited in NCBI databases. (E) The potential presence of two epitopes in the virtual VTG peptide allowed the biotechnological synthesis of two peptides (peptide 1 and peptide 2) which were used to create two different antibodies for ELISA experiments (F) to detect the VTG in the females of $P$. elephas in the second stage of egg maturation. 


\section{Tables}

Table 1. CODEHOP oligonucleotides used in PCR experiments and peptides chosen by the CODEHOP programme for the design of the primers. Each primer presents the consensus clamp given in the upper case, whereas the degenerate core is in the lower case: $y=[C, T] ; r=[A, G]$, and $n=[A, G, C, T]$. The position and orientation of each primer is reported in the Supplementary information (Fig. S1).

\begin{tabular}{|c|c|}
\hline CODEHOP Sequences & Comments \\
\hline 5'- GGCCGCCGACATCCCTCGGTGCTCCacngartgycc -3' & $\begin{array}{l}\text { F1 sense primer designed on the conserved } \\
\text { peptide YGGTTQLCSTECP }\end{array}$ \\
\hline $5^{\prime}$ - CGTCAACTCCGGCATGAACGTCACCgaracngaygt -3' & $\begin{array}{l}\text { F2 sense primer designed on the conserved } \\
\text { peptide TVNSGINVTETDV }\end{array}$ \\
\hline 5'- GGGCGAGAAGGTGATCGTGATGAAGgaraaraayca -3' & $\begin{array}{l}\text { F3 sense primer designed on the conserved } \\
\text { peptide EGEKVIVVKEKNH }\end{array}$ \\
\hline 5' - CCGGCCCGCCT ACGGCATCTACAAGtaygtngargc -3' & $\begin{array}{l}\text { F4 sense primer designed on the conserved } \\
\text { peptide VRPAYGIYKYVEA }\end{array}$ \\
\hline 5' - CCTGGCCATCTTCAAGGCCCTGGGCaayatgggngt -3' & $\begin{array}{l}\text { F5 sense primer designed on the conserved } \\
\text { peptide ALAILKALGNMGV }\end{array}$ \\
\hline 5'- CGCCCGGTTCGAGGGCATCGAGTCCathathgarga -3' & $\begin{array}{l}\text { F6 sense primer designed on the conserved } \\
\text { peptide GARFEGIESIIEE }\end{array}$ \\
\hline $\begin{array}{c}5^{\prime} \text { - TGGACTCCTCGATGGGCAGAGGAGCyttnarccangg - } \\
3^{\prime}\end{array}$ & $\begin{array}{l}\text { R1 antisense primer designed on the } \\
\text { conserved peptide PWLKAPLPIEESK }\end{array}$ \\
\hline 5'- TGGCCCTGCCGTTCACGATCTCCTGnaccatnacytt -3' & $\begin{array}{l}\text { R2 antisense primer designed on the } \\
\text { conserved peptide KVMVQEIENGRAT }\end{array}$ \\
\hline 5'- GGCCCAGGATGAAGCCTCGCACCTGngtrttytcytc -3' & $\begin{array}{l}\text { R3 antisense primer designed on the } \\
\text { conserved peptide EENTQVRGFILGH }\end{array}$ \\
\hline 5'- GGT AGGTCTCGGCCTTGATGTTCAGnarytccatytt -3' & $\begin{array}{l}\text { R4 antisense primer designed on the } \\
\text { conserved peptide KMELLNIKAETYL }\end{array}$ \\
\hline
\end{tabular}


bioRxiv preprint doi: https://doi.org/10.1101/2021.08.26.457825; this version posted August 26, 2021. The copyright holder for this preprint (which was not certified by peer review) is the author/funder. All rights reserved. No reuse allowed without permission.

\section{Supplementary information}

447

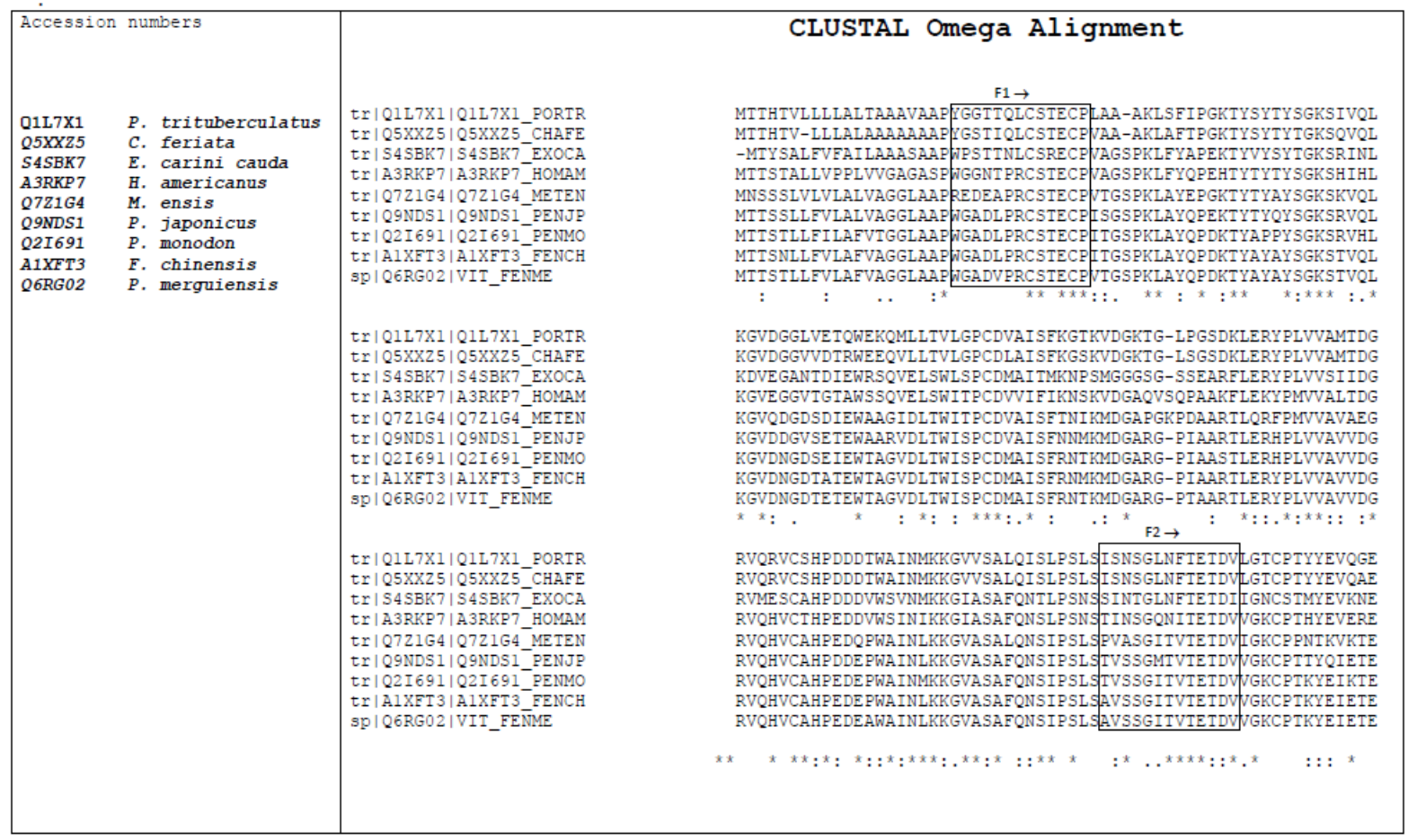

tr|Q1L7X1|Q1L7X1_PORTR tr|Q5XX25|Q5XX25 CHAFE tr|S4SBK7|S4SBK7 EXOCA tr|A3RKP 7 | A3RKP 7_HOMAM tr $1072164 \mid 072164$-METEN tr|Q9NDSI|Q9NDS1_PENJP tr|Q2I691|Q2I691 PENMO tr|A1XFT3|A1XFT3 FENCH sp | Q6RG02|VIT_FENIME

tr|Q1L7X1|Q1L7X1_PORTR tr|Q5XXZ5|Q5XX25_CHAFE tr|S4SBK7|S4SBK7_EXOCA tr|A3RKP 7 A3RKP7 HOMAM tr|0721G4 I0721G4 METEN trlo7216410721G4_METEN tr|Q9NDS1/02NDS1_PENUP tr|Q21691/21691_PENMO sp | Q6RG02|VIT_FENME

tr|Q1L7X1|Q1L7X1_PORTR tr|05XX25|05XX25 CHAFE tr|S4SBK7|S4SBK7 EXOCA $\operatorname{tr} \mid$ A3RKP $7 \mid$ A3RKP7 HOMAM tr|0721G4|0721G4 METEN tr|Q9NDSI|Q9NDS1 PENJP tr|Q2I691|Q2I691 PENMO tr|A1XFT 3 |A1XFT3 FENCH sp | Q6RG02 |VIT_FENMME
$\mathrm{F}_{3} \rightarrow$ $\leftarrow R 1$

5A.RVLVKKEKNH LLCKEHYPTPDEINL YLKGPLPIQESR PICRQEI DSGIISSVVCEDK GAKVLVKKEKNHRLCQEHYPTPDEI DLPHLKGPLPIQESQ

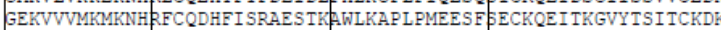
GHKV IVKKEKNH RLCKKRY PT PAETQM WLKGP LPLEESE ERCKQEI TNGIY SSI ICHDK GRELIVTKEKEH RHCTEHFPTPNEVPA WWMAPLPLEESGEECKQVIENGIYTAITCEDK GEKVIVVKEKNH RHCQQRY PTPAET PAPWLKAPLPIEESK EECKQEI TNGIYTSIMCHDK GEKVIVVKEKNH RHCQERYPTPAET PAPWLKAPLPIEESK QCRQEIANGIYTAITCQDK GEKVIVVKEKNH RHCOERY PTPAET PAPWLKAPLPIEESK POCRQEI ANGIYTAITCODK GEKVIVVKEKNH RHCQERY PTPAALPAEWLKAPLPIEESK QCRQEIANGIYTAITCQDK

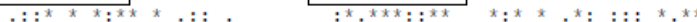
F4 $\rightarrow$

KVIRPSYGIYKYVEAKQESTLKLTSSDVSAPDTISRIGQDELVPRSLRY DYE PAKKDPTI KVIRPSYGMYKYVEAKQESTLRLTSSDVSAPDTISRIGQDELVPRS LRY DYETAKKDPSL NT RAUGSU NT K JRPSTGATKVE LRQESILRYVSLSSQ-Q--PPAIPQGSLVRKSLRY SYHTLNKDPSM H RR

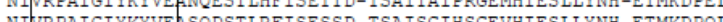
N N R RATGIYKY E

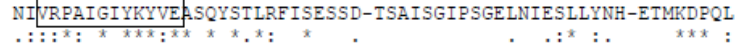

VPELEQTLRYLCEITRDGVEADTAAQLEKAVNLMRRIPEQSFNDIYTKVRNKQICPQHTK VPELEQTLTYLCEITKDGVEADVAAHLSKAVHLMRRIPEQGFNE IYTKVHNKQICPQHSR VVKLDAMLKEVCQKMKHGVQEDTAS YFANALQYMRRVPEEAIPQTLEKIRGGQICEQRQK VAELDQTMTQICEKTKDVVERDA.A.LVAKAVQLLRRVPEEAVKQTLDKIRAGRYCQDHSK APEIDELMKEICDKTENTVEA.DA_A_ALVDKALHMLRSVPAEVVEEVAEKVRGGRYCGHSER APELDQLMKE ICEKTKDTVEAEAA_L LVAKALHLLRRVPETVVVE IAQKVRQGHYCSDSAK A.PELDELMKE I CAKTKDTVEAEA.A.LVAKALLHVLRRVPETIVVETAOKVROGHYCSDSAR APELDELMKE ICDKTKDTVEAEAGALVAKAL HVLRRVPETVVVETAOKVROGHYCSDSAR APELDELMKE ICDKTKDTVEAEAGALVAKALHVLRRIPDTVVVE TAOKVROGHYCSDSAR

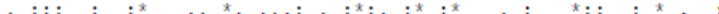


bioRxiv preprint doi: https://doi.org/10.1101/2021.08.26.457825; this version posted August 26, 2021. The copyright holder for this preprint (which was not certified by peer review) is the author/funder. All rights reserved. No reuse allowed without permission.

tr|Q1L7X1|Q1L7X1_PORTR tr $105 \times 2 \times 25105 \times \times 25^{-}$CHAFE tr|S4SBK7|S4SBK7 EXOCA tr | A3RKP7 | A3RKP7 HOMAM tr $1072164 \mid 0721$ G4 METEN tr| Q9NDS1 | Q9NDS1_PENJP tr|Q2I691|Q2I691_PENMO tr|ATXF13|AIXF_FENCH sp | Q6RG02 |VIT_FENME

Tr|01L7X1|Q1L7X1_PORTR tr $|05 \times X 25| 05 \times X 25$ CHAFE tr|S4SBK7|S4SBK7 EXOCA tr| A3RKP7| A3RKP7 HOMAM tr | 0721G4|0721G4 METEN tr|Q9NDS1 | Q9NDS1 PENJP tr102I691/Q2I691_PEMMO tr | A1XFT3 | A1XFT3 FENC sp | Q6RG02 |VIT_FENME

tr|01L7X1101L7X1_PORTR tr $105 \times X 25105 \times \times 25$ CHAFE

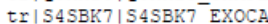
tr|A3RKP7|A3RKP7 HOMAM $\operatorname{tr} 1072164 \mid 07214^{-}$METEN tr l O9NDS1 109NDS1-PENJP tr| Q2I691| Q2I 691_PEMMO tri AIXIT) AIXFT3 FENCH sp | Q6RG02 |VIT_FENTME

YALRPEENTEVRTAAYLAAVRCANYEDLOETVTKISY--- EENTOVRGFILSH TNLOKS YALRPENTEVRIAAYLAAVRCANYELQEIVTKISY-- EENTQVRGF ILSH INLQKS YALRPGQNTEVRIAAYLAANRCANYEDLQHIVTKISY-- EENTQVRGFILSHEINLQQS VVLDPKKKTEVRIGSYLAAVKCAKYEDLKKI TDKIAI--A AENTQVRSFILSHLQNVRES IAVHPAKNIERRIASYLMAMRCVRQKDLQMIVNNTYHEKA SKNTQVRGF ILSHELNLQDI

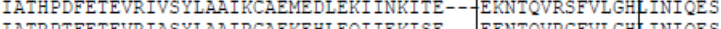
TARPTFETEVRASTLAAIRCAEREHLEOITEKTSE-CEENOVRGFLGH TNIQES IAVRPAFGIEVRIAS LAAIRCAEMEDLEEIFEKISV-- EENTQVRGF ILGHELNIQES IAVRAREIEVRIASTLAAVRCAEQEHLETITEKISK- EENOVRGFVLGH TNIQES

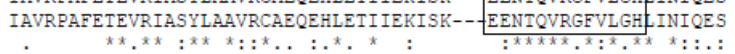

DAPEKQSLRYMMTNIVL PQDFEADIRKYSQNLDLSYFSESLGVGAEVESNLIYAPGSMIP DAPGKQRLRYLLTNILLPQDFETDIRKYSONLDLSYFSPSA---AGLESNMTYAPGSMLP TA.SFKGNLKNMLETIVL PSNFTKDWRKI SRNVDLSYYAPTFGVGAGMESNLIYAPGSFVP NTPHKDYLRYLL TNTLL PRDYKT DFRKY SRNIDMSYFAPSLGVGAGVESNIIYVPGSFVP TCPSKEHLRYLITDFVI PTDEERDFRRVSRNVMMGYHSAAFEMGADVESNIIYAPGAFVP TCPTKENLKYLLTNVVI PTDFEKDFRKE SRNVEMSYHAPAFGMGADLESNITYAPGSFIP TCPTKEHLRYLLTNEVI PIDFERDFRKF SRNIDVAYHA.PAFGMGAGLESNI I YAPGSFTP TCPAKENLRYLLANVYI PTDFERDFRKF SRNTDMAYHAPAFGMGAGLESNTIYAPGSFVP TCPAKENLRYLLANV-IPTDFERDFRKESRNIDVAYHAPAFGMGAGLESNTTYADGSEVR

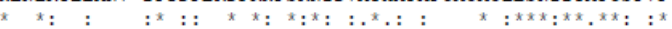

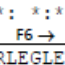

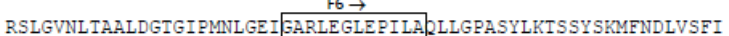
RSLGVNLTAAPDGIGIPINIADV FARVEGLEPI IA. LLLGPASYLKTSSY SKIFNDLVSFI RSWILILIGALAA-RSVDFNF TAAFE G--ISMNI GEV GARLEGLEPVIEEVF GPEGILORTSF SQILTDMTIFV RALINMILKADIDE- GLDIGE GARIGVDII

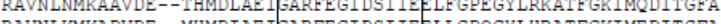
RAWLKMKADVDE-WMDIAE RAVWMKMKADVDE--THMDIAE IFRFEGVDSIIELLLGPOGYLRRATFGKIMEDITGFA

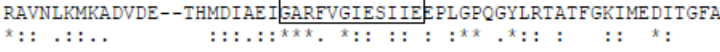

Tr|Q1L7X1|01L7X1_PORTR tr| $05 \times 25105 \times 255^{-}$CHAFE tr|S4SBK7|S4SBK7 EXOCA tr | A3RKP7 | A3RKP7_HOMAM $\operatorname{tr}|072164| 0721 \mathrm{G} 4$ METEN tr|Q9NDS1|Q9NDS1 PENJP tr|Q2I691|Q2I691 PENMO tr|A1XFT3|A1XFT3 FENCH sp | Q6RG02|VII_FENME

Tr|Q1L7X1|Q1L7X1_PORTR $\operatorname{tr} 105 \times \times 25105 \times \times 25$ CHAFE $\operatorname{tr} \mid$ S4SBK7|S4SBK7 EXOCA tr|A3RKP7|A3RKP7 HOMAM tr $1072164 \mid 072164$ METEN tr 109 NDS1 109 NDS1 PENJP $\operatorname{tr} 1$ Q21691/Q21691_PEMMO tr|AIXFS|AIXFI3_FENCH sp | Q6RG02|VII_FENME

$\operatorname{tr}|01 L 7 \times 1| 01 L 7 \times 1$ PORIR tr $105 \times 25105 \times \times 25$ CHAFE tr|S4SBK7|S4SBK7 EXOCA tr | A3RKP 7 |A3RKP7 HOMAM tr $1072164 \mid 0721$ G4 METEII tr I Q9NDS1 I Q9NDS1 PENJP tr|Q2I691|Q2I691_PENMO tr|AIXFT 3|A1XFT3 FENCH sp | Q6RG02 |VIT_FENMME $\leftarrow R 2$

LESLFMDAIAFVHEPESV PVMVKELVEGRTT|FTLAALYSTAFYLVPRPDVKAIQALEPLF LESMYKDAIAFVHEPESV PVMVKELVEGRAT ETLAALY STGFYLVPRPDVKAIRALEPLF LESMF LDGLAFVYESGAV KVMVQELVSGKAT GGRAALYAASMYFMPRPCIHS IEALKPLF LESLFL DAVSFI HESGAV KVMVDELVMARAT VS RAALYT AAAFYLQPRPCI HAMMALKRMF LESIFFDAVAFVHESGAVKVMVEEIENGRAT GGRLALYTAALLYFT PRPNIKAVEALTPLF LESI FLDAVAFL LESGAVKVMVOEI LNGRATEGRLALYTAALYYLTPRPNIEAVKALTPLF LESIFLDAVAFL LESGAVKVMVHEIENGRAT GGRLALYMAAVYLTPRPNIEAVKALTPLF LESIFLDAVAFL HESGAV KVMVHEIENGRAT GGRLALYTAALLYLTPRPNIEAVKALTPLF LESIFLDAVAFI HE SGAVKVMVNEIENGRAT GRLALYTAALYYL I PRPNIEAVKALTPLF

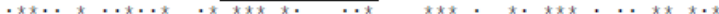

KSSADLS SAKLA.AASMVNTYCRHKPHCYNET PVRNLAOALKOKIEEDLSSSS-EDTQKQA KSNADLSSAKLAAAASMVNTYCRHKPHCYEES PVRNLAQALKKQKIEEDLSSSSREETQKQA ESSOPLPRATLAAASMVNTYCRHNHCY EEAPVKSLVEALGNKLOROCSPSADERTQKAA ESOPDPRA LARA

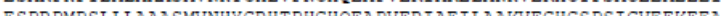

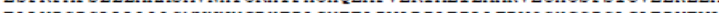
EALMPSPSLLLAAA ESPRMP SLLLAAA.SMNICRATACTEKAPVAGIAEILANRVQSHCSPSAGVEDKEVA ESPRPMP SLLLAAATMVNHYCRHTPACYEKAPVARIAEILANRVOTHCSPSAGVEDNEVA$$
\mathrm{F5} \rightarrow
$$

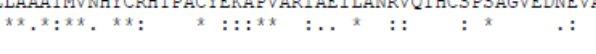

ESALKSLGNMGVUTPEVAEKVVL YMENENKKVSARSRC-TSLQADRVS---RPVTQKLVH LSALKSLGNMGVMTPETADKVIL YMENENKKVSTRVA_A_AAFRLTKCQ---RLVTQKLVQ EVLLKSL GNMGVMNSEMARP IMQCIENSEADQGIRIAATQAFRNVRCTPEIHPAIKQLIN LATLKTLGNMGVMTQEVARFVMTCVDTEGVKINVRVA_A.AQAFRQVKCE---RHQTEHLVN VA.ALKAL GNMGV VTPAVTSAAVTCIEEHEVPTS IRVA_A.AEVFRQAKCY---RPAVEKLVD LAIFKALGNMGVVTPAVTRA.AAOCIEKEGLETSIRVA.AQARFRQANCD---RPAVQKLVD LAIFKAVGNMGVITPAVTRA.AVACIEQEGVETS IRVAAAAHVFRQTKCY---RPAVEKLVS LAIFKAIGNMGV ATPAVTRAAVHCIEEEGLETSIRVAAAQAARQANCF---RPAVEKLVD EAIFKTI GNMGVATPAVTRA.AVHCIEVEGLETSVRVAAAEAFRQANCF---RPAVEKLVD

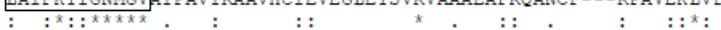






Fig. S1. Multiple alignment of VTG amino acid sequences from nine different crustacean sources. The sequences were chosen from the GenBank SwissProt database and aligned using Clustal Omega (https://www.ebi.ac.uk/Tools/msa/clustalo/). The figure shows the alignments based upon which the CODEHOP primers have been designed. An asterisk $\left(^{*}\right)$ denotes identical residues; a colon (:) denotes a conserved residue substitution; a full stop (.) denotes partial conservation of the residue. The arrows above the amino acid sequences indicate the position of the sense $(\mathrm{F} \rightarrow)$ and antisense $(\leftarrow \mathrm{R})$ primers chosen from a group of candidate primers obtained from the j-CODEHOP programme. The sequences of the sense and antisense primers, shown inside the boxes, were obtained from the Clustal Omega alignments. 


\begin{tabular}{|c|c|c|}
\hline \multicolumn{3}{|c|}{ Clustal Omega alignment } \\
\hline P.elephas & - TLPRQLRSPLAQGPLPEESGSVCLQEIKDGIYWSITCEDE & 42 \\
\hline QDE13857.1 & GEKVVVTKL KNHRFCQDHYANRAETPKAWMKAPL PMEESYSECKQE I TNGI YTS ITCKDK & 112 \\
\hline ABO09863.1 & GHKVIVKKE KNHRLCKKRY PTPAETQMPWLKGPL PLEESECRCKQE I TNGI YSSI I CHDK & 240 \\
\hline & $: . * * *: * * * . * * * * .: * * * * * * . *:$ & \\
\hline P.elephas & NVIRPSYGAYKYVEANQESTT-1 & 63 \\
\hline QDE13857.1 & NVIKPAYGS YKYVEAHQESVLRFQSETDQIPPSVSQLPSRFIRKTLRYDQHTLKKDPSMA & 172 \\
\hline ABO099863.1 & 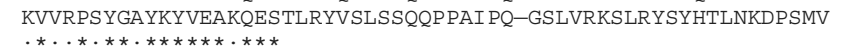 & 298 \\
\hline QDE13857.1 & Macrobrachium potiuna (69.39\% identity) & \\
\hline ABO09863.1 & Homarus americanus & \\
\hline
\end{tabular}

471 GenBank. Identity and similarity percentages are shown at the top of each Clustal Omega alignment panel.

472 Numbers on the left indicate the positions of the amino acids in each protein. An asterisk (*) denotes 473 identical residues; a colon (:) denotes a conserved residue substitution; a full stop (.) denotes partial conservation of the residue.

475 
490

491

492

493

494

495

496

497

498

499

500

Table 1S. (A) Number of ovigerous P.elephas females captured inside (IN) and outside (OUT) FPAs, their size range and egg diameter. The presence of external eggs on the pleopods and carapace length (CL) was used as an indicator of maturity (B) Number of ovigerous females and the estimated VTG concentration range inside and outside FPAs. The VTG concentration in relationship with the inside and outside FPAs did not show statistic differences (Fisher's exact test statistic $=1 ; \mathrm{p}>0.05)$.

A

\begin{tabular}{|c|c|c|c|c|}
\hline $\begin{array}{c}\text { FPAs } \\
\text { (Su Pallosu and } \\
\text { Buggerru })\end{array}$ & $\begin{array}{l}\text { P. elephas } \\
\text { females }\end{array}$ & CL range mm & Egg stage & Egg diameter mm \\
\hline IN & 16 & $60.9-91.9$ & 2 & $0.90-1.3$ \\
\hline OUT & 14 & $68.7-100.3$ & 2 & \\
\hline & & & & \\
\hline
\end{tabular}

B

\begin{tabular}{|c|c|c|}
\hline $\begin{array}{c}\text { P. elephas } \\
\text { females }\end{array}$ & $\begin{array}{c}\text { VTG 120-180 } \\
\mathrm{ng} / \mathrm{mL}\end{array}$ & $\begin{array}{c}\text { VTG 200-260 } \\
\mathrm{ng} / \mathrm{mL}\end{array}$ \\
\hline FPAs IN & 8 & 8 \\
\hline FPAs OUT & 6 & 8 \\
\hline Column Totals & 14 & 16 \\
\hline
\end{tabular}

